\title{
Primed Lettuce Seeds Exhibit Increased Sensitivity to Moisture Content During Controlled Deterioration
}

\author{
H.J. Hill and Jesse D. Cunningham \\ Seed Dynamics, Inc., 1081-B Harkins Road, Salinas, CA 93901
}

Kent J. Bradford
Department of Plant Sciences, One Shields Avenue, University of California,
Davis, CA 95616-8780

A.G. Taylor ${ }^{1}$

Department of Horticultural Sciences, New York State Agricultural Experiment Station, Cornell University, Geneva, NY 14456-0462

Additional index words. Lactuca sativa, seed priming, aging, viability equation, germination

Abstract. The Ellis-Roberts seed viability equation is used to predict seed survival after storage at specified temperatures and moisture contents. Seed priming, which can break dormancy and accelerate germination, can also reduce seed storage life. Because primed seeds were not used in developing the Ellis-Roberts equation, the reciprocal nature of specific seed moisture content (MC, fresh weight basis) and temperatures that applies to nonprimed lettuce (Lactuca sativa $L$.) seeds may not apply to primed seeds. To determine how priming affects lettuce seeds in relation to the viability equation, an experiment was conducted using two cultivars, 'Big Ben' and 'Parris Island Cos'. Seeds primed in polyethylene glycol $8000\left(-1.45 \mathrm{MPa}, 24 \mathrm{~h}\right.$ at $\left.15{ }^{\circ} \mathrm{C}\right)$ and nonprimed seeds were first adjusted to $6 \%$ and $9 \%$ moisture contents and then stored at 48 and $38{ }^{\circ} \mathrm{C}$ for up to 30 days, respectively. These storage conditions $\left(6 \% \mathrm{MC}\right.$ and $48{ }^{\circ} \mathrm{C} ; 9 \% \mathrm{MC}$ and $\left.38{ }^{\circ} \mathrm{C}\right)$ were predicted by the viability equation to result in equal longevities. Subsequent viability assays at $20{ }^{\circ} \mathrm{C}$ revealed that nonprimed seeds in both storage environments exhibited similar losses in viability over time, thus validating the Ellis-Roberts equation and the use of these conditions to apply different but equal aging stress. Primed seeds of both cultivars deteriorated faster than nonprimed seeds as expected. However, primed seeds did exhibit different rates of deterioration between the storage environments. Primed seeds stored at $9 \% \mathrm{MC}$ and $38{ }^{\circ} \mathrm{C}$ deteriorated faster than primed seeds stored at $6 \% \mathrm{MC}$ and $48{ }^{\circ} \mathrm{C}$. The rate of decline in probit viability percentage was three times greater in primed 'Big Ben' seeds stored at $9 \% \mathrm{MC}$ and $38^{\circ} \mathrm{C}$ than for those stored at $6 \% \mathrm{MC}$ and $48^{\circ} \mathrm{C}$ ( -1.34 versus $-\mathbf{0 . 2 6}$ probits per day, respectively). 'Parris Island Cos' seeds stored at $9 \% \mathrm{MC}$ and $38{ }^{\circ} \mathrm{C}$ had twice the rate of deterioration that those stored at $6 \% \mathrm{MC}$ and $48{ }^{\circ} \mathrm{C}(-1.19$ and -0.49 probits per day, respectively). The results indicate that primed lettuce seeds were more sensitive to the adverse effects of higher seed MC than were nonprimed seeds during storage at elevated temperatures.

Seed priming is a term used to describe any number of postharvest, presowing hydration treatments whose purpose is to improve seedling establishment (Taylor and Harman, 1990). Reports across a collection of species as diverse as sweet corn [Zea mays 'Saccharata' L. (Parera and Cantliffe, 1994)], tomato [Lycopersicon esculentum Mill (Alvarado and Bradford, 1989)], parsley [Petroselinum crispum (P. Mill.) Nyman ex A.W. Hill (Pill and Kilian, 2000)], and warm-season grasses (Bush et al., 2000) have documented that priming increases the rate of germination

Received for publication 12 Mar. 2007. Accepted for publication 29 Apr. 2007.

${ }^{1}$ To whom reprint requests should be addressed; e-mail agt1@cornell.edu.
1989). In lettuce, any priming protocol that improved seed germination rate decreased longevity faster than the nonprimed control seed under controlled deterioration conditions (Tarquis and Bradford, 1992). Even under milder storage conditions $\left(45^{\circ} \mathrm{C}\right.$ and $50 \%$ relative humidity), primed lettuce seeds exhibited slower and less synchronous germination than the nonprimed seeds in as little as $14 \mathrm{~d}$ (Hacisalihoglu et al., 1999).

The seed viability equation (Ellis and Roberts, 1980) used to describe orthodox seed longevity in relation to seed moisture content (MC) and temperature (T) is:

$$
\nu=\mathrm{K}_{\mathrm{i}}-(1 / \sigma) p
$$

where $\nu$ is the probit of percent viability after a period of $p$ (days) in storage at a given $\mathrm{MC}$ and $\mathrm{T}\left({ }^{\circ} \mathrm{C}\right), \mathrm{K}_{\mathrm{i}}$ is an index of the initial seed quality of the lot, and $\sigma$ is defined as the standard deviation of individual seed lifespans and varies with storage conditions according to the following equation:

$$
\log \sigma=\mathrm{K}_{\mathrm{E}}-\mathrm{C}_{\mathrm{w}} \log \mathrm{MC}-\mathrm{C}_{\mathrm{H}} \mathrm{T}-\mathrm{C}_{\mathrm{Q}} \mathrm{T}^{2}
$$

The constants $\mathrm{K}_{\mathrm{E}}, \mathrm{C}_{\mathrm{w}}, \mathrm{C}_{\mathrm{H}}$, and $\mathrm{C}_{\mathrm{Q}}$ are species constants used to quantify the relative effects of seed moisture $\left(\mathrm{C}_{\mathrm{w}}\right)$ and temperature $\left(\mathrm{C}_{\mathrm{H}}\right.$ and $\left.\mathrm{C}_{\mathrm{Q}}\right)$ on longevity. The $\mathrm{K}_{\mathrm{E}}$ constant provides a measure of the sensitivity of a species to the effects of temperature and moisture on seed longevity (Roberts, 1986).

This equation has been shown to be valid for a wide range of plant species and storage conditions, including lettuce (Kraak and Vos, 1987). The advantage of this equation in predicting lettuce seed aging is that different temperature and $\mathrm{MC}$ values can be inserted to determine how $v$ (probit of percent viability) varies with storage duration $(p)$. Different reciprocal inputs (i.e., increased T along with decreased MC) can be selected that would predict the same rate of deterioration.

The purpose of this study was to test whether reciprocal $\mathrm{T}$ and $\mathrm{MC}$ environments predicted by the viability equation to result in the same rate of deterioration in nonprimed seeds would result in the same relative rate of deterioration, albeit a more rapid one, for primed lettuce seeds. The specific constants proposed by Kraak and Vos (1987) for predicting lettuce seed longevity were developed using nonprimed seeds. Because priming causes a shorter shelf life, the use of these constants in the viability equation would not be expected to predict accurately the longevity of primed lettuce seeds. However, deviations from this expectation might reveal what aspects of seed longevity are altered by priming.

\section{Materials and Methods} tion percentage after 3 months of storage than the nonprimed control seed (Chiu et al., 2002). Primed tomato seeds exhibited delayed germination and a lower mean germination when stored at $30{ }^{\circ} \mathrm{C}$ for 6 months as compared with the control (Argerich et al.,
Seeds of two genetically distinct lettuce cultivars were obtained from Pybas Seed Co. (Salinas, CA). 'Parris Island Cos' is a whiteseeded romaine and 'Big Ben' is an iceberg type. Seeds of both cultivars exhibited a high 
germination percentage ( 99 or greater). Seeds were stored at $5{ }^{\circ} \mathrm{C}$ before use.

To prime seeds, $200 \mathrm{~g}$ were incubated for $24 \mathrm{~h}$ at $15^{\circ} \mathrm{C}$ in an aerated $2-\mathrm{L}$ solution of Carbowax PEG 8000 (336 g. $\left.\mathrm{L}^{-1},-1.45 \mathrm{MPa}\right)$ (Dow Chemical, Midland, MI) (Bradford, 1986) in a $2.5-\mathrm{L}$ acrylic container. After priming, seeds were rinsed to remove residual PEG and then allowed to dry overnight on paper towels at room temperature. Seeds were then placed in sealed bottles and stored at $5{ }^{\circ} \mathrm{C}$ before use. To determine priming efficacy, four replicates of 100 primed and nonprimed seeds from both cultivars were vacuum-planted on two premoistened (with $18 \mathrm{~mL}$ of water) brown blotter papers (Grade 628; Ahlstrom Corp., Mt. Holly Springs, PA) and placed in $11 \times 11-\mathrm{cm}$ clear plastic boxes (model 156-C; Pioneer Packaging, Dixon, $\mathrm{KY}$ ). Boxes were immediately covered with aluminum foil and incubated at $30^{\circ} \mathrm{C}$ for $4 \mathrm{~d}$. A seed was scored as germinated (viable) if a radicle was visible. Time needed for $50 \%$ of the total radicles to emerge (time to $50 \%$ viability) was determined using three replicates of 100 seeds from both cultivars planted as described previously and incubated at $20{ }^{\circ} \mathrm{C}$ with a $12 \mathrm{~h} / 12 \mathrm{~h} \mathrm{light/dark}$ photo cycle. The number of visible radicles was counted every 30 min from hour 16 until hour 20 after planting. Viability data were then transformed into probits for each replication and plotted against time (h) to yield a linear relationship for each replicate. Time to $50 \%$ of viability was calculated from each equation and then averaged to yield a mean time (h) to $50 \%$ viability.

All MC (fresh weight basis) measurements were made by oven drying six $1-\mathrm{g}$ replicates for $1 \mathrm{~h}$ at $130{ }^{\circ} \mathrm{C}$. Primed and nonprimed seed MC was adjusted to $6 \%$ or $9 \% \mathrm{MC}$ by removing water using desiccant bags containing $\mathrm{CaSO}_{4}$ (A.W. Hammond Drierite, Xenia, $\mathrm{OH}$ ) or by adding water using the following formula:

$$
\begin{aligned}
\text { Water added }= & {\left[\left(\mathrm{MC}_{\text {desired }}-\mathrm{MC}_{\text {initial }}\right) \times\right.} \\
& \text { seed wt }] /\left[100-\mathrm{MC}_{\text {desired }}\right] .
\end{aligned}
$$

Seeds were stored at $5{ }^{\circ} \mathrm{C}$ during equilibration and constantly mixed on a Wheaton roller apparatus (Fisher Scientific, www. fishersci.com) to ensure adequate distribution of moisture. Treatments required between 2 and 3 weeks of equilibration and adjustments to obtain their target MC. After MC adjustment, primed and nonprimed seed of each cultivar $\times$ aging environment were divided into 10 sample dates consisting of four replications each. Each replicate contained $2.5 \mathrm{~g}$ of seeds in a 5-mL glass bottle sealed in parafilm. All four replicates of a sample date were sealed together in foil-lined polybags (part number TF-900; Techflex Packaging, Hawthorne, CA) and submerged in water baths maintained at 38 or $48{ }^{\circ} \mathrm{C}$ (for up to $30 \mathrm{~d}$ ). Sample dates were removed from the water bath at time intervals previously determined based on preliminary experiments. Primed seed samples were removed daily from the water baths after $\approx 3 \mathrm{~d}$ of storage. Nonprimed seed samples were removed from the water bath approximately every $3 \mathrm{~d}$ after 2 weeks of storage. After storage and before planting, two 1-g seed samples from each replicate within each sampling date were used for a final MC determination. These MC data were averaged over replications. Only seeds from sampling dates for which mean MC (averaged across the four replicates) were found to be within the target $\mathrm{MC} \pm 0.1 \%$ after storage were used in data analyses.

To determine percent viability after storage, 100 seeds each of the four replicates were planted at $20{ }^{\circ} \mathrm{C}$ with a diurnal $12 / 12$ light/dark cycle [Association of Official Seed Analysts (AOSA), 1993]. After 7 d, seeds were counted and classified into normal, abnormal, and nongerminated according to AOSA seedling evaluation guidelines (AOSA, 1992). Only seedlings classified as normal were used in the analyses.

$\mathrm{MC}$ and temperature values used to define the two storage environments were obtained from using the Ellis-Roberts equation (Ellis and Roberts, 1980) using the species constants for lettuce published by Kraak and Vos (1987): $\mathrm{K}_{\mathrm{E}}=6.895, \mathrm{CW}=$ $4.2, \mathrm{CH}=0.0329, \mathrm{CQ}=0.000478$. Storage environments of $6 \% \mathrm{MC}$ at $48{ }^{\circ} \mathrm{C}$ and $9 \% \mathrm{MC}$ at $38{ }^{\circ} \mathrm{C}$ were predicted to result in identical viability loss time courses. Viability data were transformed to probits and analyzed using CoStat (Cohort Software, www. cohort.com).

\section{Results and Discussion}

Priming increased the percentage of seeds that could germinate at $30^{\circ} \mathrm{C}$ in darkness and decreased the time to radicle emergence at $20{ }^{\circ} \mathrm{C}$ in light in both cultivars (Table 1). These results confirm the beneficial effects of priming to improve lettuce seed germination under adverse environmental conditions (Hill et al., 1989; Tarquis and Bradford, 1992; Valdes et al., 1985).

A combined MC was calculated for seeds from each of the eight storage treatments (cultivar $\times$ seed treatment $\times$ storage environment) by averaging the mean MC from each sampling date used. These seed MCs representing each of the eight storage treatments closely approximated the targeted values sought (Table 2).

Primed seeds of both cultivars deteriorated faster than their respective nonprimed controls within both storage environments (Figs. 1A and 2A). The faster deterioration of primed than of nonprimed seeds confirms reported results in lettuce (Tarquis and Bradford, 1992), impatiens (Impatiens walleriana L.), and pepper (Capsicum annuum L.) (Buitink et al., 2000) as well as other crops.

A constant rate of seed deaths over time was observed in both storage treatments and is illustrated by the linear decline in probit viability in Figures $1 \mathrm{~B}$ and $2 \mathrm{~B}$ (Ellis and Roberts, 1980; Tarquis and Bradford, 1992). This constant rate of decline in probit viability or slope is the reciprocal of the standard deviation of the normal distribution of seed deaths over time (represented by the symbol: $1 / \sigma$ ) (Ellis and Roberts, 1980; Roberts, 1986). The normal distribution of primed seed deaths recorded over time confirms that priming does not cause a change in seed death distribution, only a change in its frequency or rate. A linear decline in probit of the percentage of primed lettuce seed deaths over time has been documented (Tarquis and Bradford, 1992).

To obtain the best estimates of $\mathrm{K}_{\mathrm{i}}$ (initial seed quality) and $1 / \sigma$, data collected before the beginning of the rapid viability decline were excluded from the probit analyses (Kraak and Vos, 1987; Tarquis and Bradford, 1992). Exclusion of this lag phase data

Table 1 . Percent viability and time to $50 \%$ total viability of nonprimed and primed Big Ben and Parris Island Cos (PIC) lettuce seeds before storage.

\begin{tabular}{llcc}
\hline Cultivar & Seed treatment & $\begin{array}{c}\text { Germination at } 30{ }^{\circ} \mathrm{C} \\
\text { dark } \% \pm \mathrm{SE}\end{array}$ & $\begin{array}{c}\text { Time to } 50 \% \text { viability } \\
\text { at } 20{ }^{\circ} \mathrm{C} \mathrm{h} \pm \mathrm{SE}\end{array}$ \\
\hline Big Ben & Nonprimed & $1 \pm 0.7$ & $21.5 \pm 0.07$ \\
& Primed & $99 \pm 0.3$ & $17.5 \pm 0.04$ \\
PIC & Nonprimed & $2 \pm 0.5$ & $21.0 \pm 0.08$ \\
& Primed & 100 & $15.0 \pm 0.06$ \\
\hline
\end{tabular}

Table 2. Moisture content (fresh weight) of nonprimed and primed lettuce seed treatments after storage averaged across sampling dates.

\begin{tabular}{lcccc}
\hline Cultivar & Seed treatment & Target MC $(\%)$ & $\begin{array}{c}\text { No. of sampling } \\
\text { dates included }\end{array}$ & $\begin{array}{c}\text { Treatment } \\
\text { MC } \% \pm \text { SE }\end{array}$ \\
\hline Big Ben & Nonprimed & 6 & 9 & $6.04 \pm 0.012$ \\
& & 9 & 6 & $8.98 \pm 0.017$ \\
& Primed & 6 & 8 & $6.04 \pm 0.037$ \\
PIC & & 9 & 8 & $8.99 \pm 0.011$ \\
& Nonprimed & 6 & 9 & $5.95 \pm 0.013$ \\
& Primed & 9 & 8 & $8.97 \pm 0.025$ \\
& & 6 & 8 & $6.01 \pm 0.024$ \\
& & 9 & 5 & $9.05 \pm 0.011$ \\
\hline
\end{tabular}

$\mathrm{MC}=$ moisture content; PIC $=$ Parris Island Cos. 

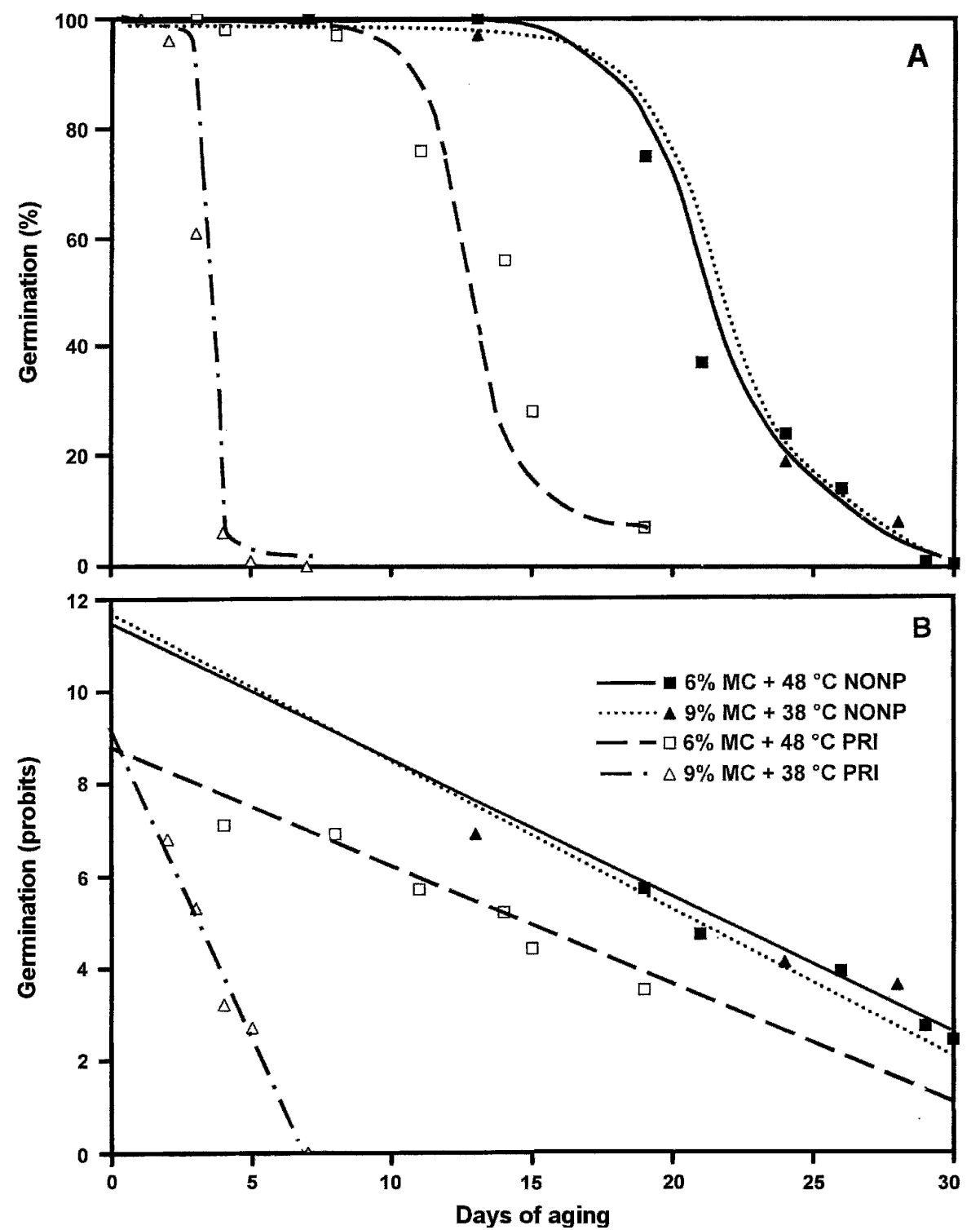

Fig. 1. (A) Viability loss curves and (B) probit viability decline for nonprimed (NONP) and primed (PRI) 'Big Ben' seeds stored at $6 \% \mathrm{MC}+48{ }^{\circ} \mathrm{C}$ and $9 \% \mathrm{MC}+38{ }^{\circ} \mathrm{C}$. Values for the y-intercepts $\left(\mathrm{K}_{\mathrm{i}}\right)$ and slopes $(1 / \sigma)$ generated by probit linear regressions are given in Table $3 . \mathrm{MC}=$ moisture content.

(defined as the time between the start of storage and the first significant decline in seed viability) allows an estimation of $\mathrm{K}_{\mathrm{i}}$ that is more indicative of the initial quality of a seed lot than can be observed using the normal germination test (Kraak and Vos, 1987). Within each cultivar, the $K_{i}$ values for the primed seed treatments tended to be lower than for the nonprimed seed treatments (Table 3), although differences were nonsignificant. Tarquis and Bradford (1992) also reported that PEG priming resulted in lower $K_{i}$ values for primed than for nonprimed seeds. A lower $\mathrm{K}_{\mathrm{i}}$ could account for the faster decline in seed viability for the primed 'Big Ben' seeds stored in the $6 \% \mathrm{MC}$ $+48{ }^{\circ} \mathrm{C}$ environment as compared with either one of the nonprimed seed-storage environmental treatments (Fig. 1A), because the $1 / \sigma$ of these three storage treatments (Table 3 ) were not significantly different according to their $95 \%$ confidence limits.

Larger differences in $1 / \sigma$ values were observed between storage environments for primed than for nonprimed seeds in both cultivars (Table 3 ). For example, the $1 / \sigma$ value for primed 'Big Ben' seeds stored in the $9 \% \mathrm{MC}+38{ }^{\circ} \mathrm{C}$ environment $(-1.34$ probits/day) was three times greater than when seeds were stored in the $6 \% \mathrm{MC}+48{ }^{\circ} \mathrm{C}$ environment $(-0.26$ probits/day); whereas the $1 / \sigma$ values for the nonprimed seeds were similar between the storage environments $(-0.32$ and -0.29 probits/day, respectively). The lack of differences in $1 / \sigma$ values for nonprimed seeds of both cultivars was predicted by the Ellis-Roberts equation and confirms its validity. For primed seeds, the large difference in $1 / \sigma$ values between storage environments $\left(6 \% \mathrm{MC}+48{ }^{\circ} \mathrm{C}\right.$ versus
$9 \% \mathrm{MC}+38{ }^{\circ} \mathrm{C}$ ) reflects the different viability loss curves observed between storage environments (Figs. 1A and 2A). The more rapid deterioration of the primed seeds at $9 \% \mathrm{MC}$ versus $6 \% \mathrm{MC}$ suggests that priming increased the sensitivity of seeds to higher MC. Modification may be needed in the current Ellis-Roberts equation if primed lettuce seed deterioration is to be better predicted. The Ellis-Roberts equation currently uses only a single constant $\left(\mathrm{C}_{\mathrm{w}}\right)$ and a log-linear relationship to account for the effects of MC on seed longevity (Roberts, 1986). If primed seeds are more susceptible than nonprimed seeds to deterioration as $\mathrm{MC}$ increases, a quadratic relationship with MC may predict more accurately the effects of moisture content on primed seed longevity.

The cause for the lack of reciprocity (between elevated seed MCs and lower storage temperatures) in viability loss rates between storage environments for primed lettuce seeds is not known. PEG priming has been shown to alter the water absorption properties of mung bean seed [Vigna radiata (L.) Wilczek] embryonic tissue by increasing the number of weak water-binding sites (Sun et al., 1997). Thus, an increase in the number of weak water absorption binding sites in primed lettuce seed could have increased the primed seed's sensitivity to moisture allowing for a faster decline in viability in the $9 \%$ MC storage as compared with the $6 \%$ (although temperature was higher in the $6 \%$ storage). However, the large $1 / \sigma$ differences between aging environments for the primed lettuce seed that we report may not solely be the result of a change in water absorption properties, if indeed they exist in lettuce. In a later study, Sun et al. (2003) showed that water absorption differences alone could not completely explain the difference in longevity between primed and nonprimed mung bean seeds, especially at moisture levels below $13 \%$. Priming, followed by drying, also caused an increase in biological surfaces of embryonic tissue in mung bean (Sun et al., 2003). A greater surface area for biological reactions to occur may also cause a greater predisposition to aging effects such that the primed lettuce seeds would age faster at $9 \%$ than at $6 \% \mathrm{MC}$ irrespective of temperature, whereas no difference would be noticed in the nonprimed seed. However, contrary to reports using mung bean seeds (Sun et al., 1997, 2003), we have not been able to detect consistent differences in seed moisture absorption isotherms between primed and nonprimed lettuce seeds (data not shown).

These results illustrate that priming can increase lettuce seed's adverse sensitivity to a heightened MC and the inability of the EllisRoberts equation to predict accurately primed seed shelf life under reciprocal (high $\mathrm{MC}$ and low temperature versus the opposite) storage conditions. The need for caution when accelerating the deterioration process of primed lettuce seeds is also recommended. Increasing $\mathrm{MC}$ above a level at which seeds 


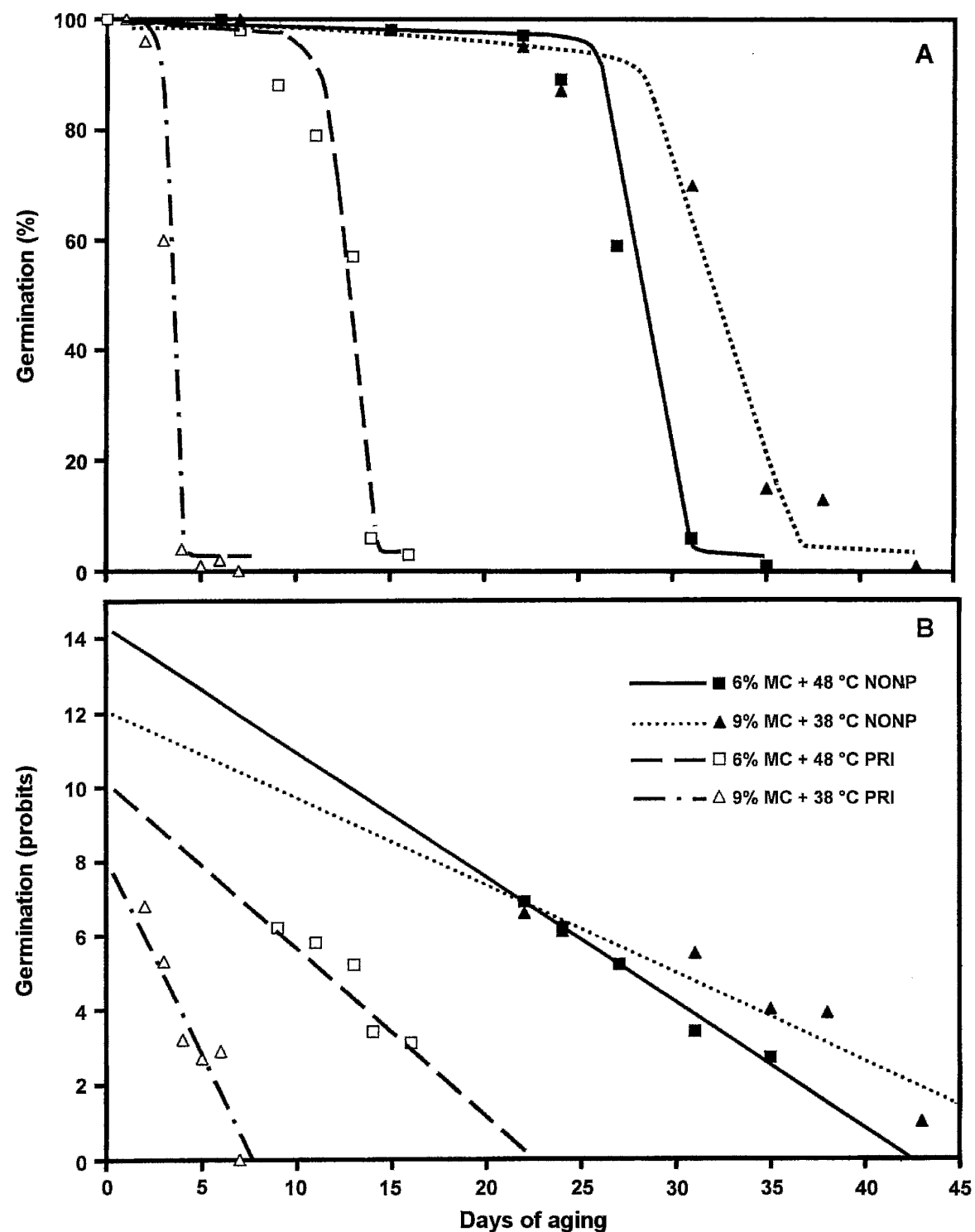

Fig. 2. (A) Viability loss curves and (B) probit germination decline for nonprimed (NONP) and primed (PRI) 'Parris Island Cos' seeds stored at $6 \% \mathrm{MC}+48{ }^{\circ} \mathrm{C}$ and $9 \% \mathrm{MC}+38{ }^{\circ} \mathrm{C}$. Values for the y-intercepts $\left(\mathrm{K}_{\mathrm{i}}\right)$ and slopes $(-1 / \sigma)$ generated by probit linear regressions are given in Table $3 . \mathrm{MC}=$ moisture content.

Table 3. Effects of seed treatment and storage environment on initial seed quality $\left(\mathrm{K}_{\mathrm{i}}\right)$ and the rate of deterioration $(1 / \sigma)$ for Big Ben and Parris Island Cos (PIC) lettuce seeds.

\begin{tabular}{lccccc}
\hline \multirow{2}{*}{ Cultivar } & Seed treatment & Storage environment & $\mathrm{K}_{\mathrm{i}}$ (probits) & $1 / \sigma$ (probits/day \pm & \\
\hline Big Ben & Nonprimed & $6 \% \mathrm{MC}+48^{\circ} \mathrm{C}$ & 11.2 & $-0.29 \pm 0.04$ & $\mathrm{R}^{2}$ \\
& & $9 \% \mathrm{MC}+38^{\circ} \mathrm{C}$ & 11.6 & $-0.32 \pm 0.28$ & $0.88^{* * *}$ \\
& \multirow{2}{*}{ Primed } & $6 \% \mathrm{MC}+48^{\circ} \mathrm{C}$ & 8.5 & $-0.26 \pm 0.08$ & $0.87^{*}$ \\
& & $9 \% \mathrm{MC}+38^{\circ} \mathrm{C}$ & 9.2 & $-1.30 \pm 0.36$ & $0.90^{* *}$ \\
PIC & Non-primed & $6 \% \mathrm{MC}+48^{\circ} \mathrm{C}$ & 14.3 & $-0.34 \pm 0.08$ & $0.99^{* *}$ \\
& & $9 \% \mathrm{MC}+38^{\circ} \mathrm{C}$ & 12.1 & $-0.24 \pm 0.11$ & $0.82^{*}$ \\
& \multirow{2}{*}{ Primed } & $6 \% \mathrm{MC}+48^{\circ} \mathrm{C}$ & 10.9 & $-0.49 \pm 0.34$ & $0.95^{* *}$ \\
& & $9 \% \mathrm{MC}+38^{\circ} \mathrm{C}$ & 8.8 & $-1.19 \pm 0.54$ & $0.98^{* *}$ \\
\hline
\end{tabular}

*** Significant at $P \leq 0.05$ and 0.01 , respectively.

$\mathrm{CL}=$ confidence limits.

are stored may underestimate the already shortened shelf life of primed lettuce seeds. A more accurate acceleration method for estimating relative deterioration of primed lettuce seeds may be to only increase storage temperature.
Argerich, C.A., K.J. Bradford, and A.M. Tarquis 1989. The effects of priming and aging on resistance to deterioration of tomato seeds. J. Expt. Bot. 40:593-598.

Association of Official Seed Analysts. 1992. Seedling evaluation handbook. No.35, AOSA, Lincoln, NE.

Association of Official Seed Analysts. 1993. Rules for testing seeds. J. Seed Technol. Vol. 16, No. 3.

Bradford, K.J. 1986. Manipulation of seed water relations via osmotic priming to improve germination under stress conditions. HortScience 21:1103-1128.

Buitink, J., M.A. Hemminga, and F.A. Hoekstra. 2000. Is there a role for oligosaccharides in seed longevity? An assessment of intercellular glass stability. Plant Physiol. 122:1217-1224.

Bush, E.W., P. Wilson, D.P. Shepard, and G. McClure. 2000. Enhancement of seed germination in common carpetgrass and centipedegrass seed. HortScience 35:769-770.

Cantliffe, D.J., K.D. Shuler, and A.C. Guedes. 1981. Overcoming dormancy in heat sensitive lettuce by seed priming. HortScience 15:196-198.

Chiu, K.Y., C.L. Chen, and J.M. Sung. 2002. Effect of priming temperature on storability of primed sh-2 sweet corn seed. Crop Sci. 42:1996-2003.

Ellis, R.H. and E.H. Roberts. 1980. Improved equations for the prediction of longevity. Ann. Bot. (Lond.) 45:31-37.

Hacisalihoglu, G., A.G. Taylor, D.H. Paine, M.B. Hildebrand, and A.A. Khan. 1999. Embryo elongation and germination rates as sensitive indicators of lettuce seed quality: Priming and aging studies. HortScience 34:1240-1243.

Hill, H.J. 1999. Recent developments in seed technology. J. New Seeds 1:105-112.

Hill, H.J., A.G. Taylor, and T.G. Min. 1989. Density separation of imbibed and primed vegetable seeds. J. Amer. Soc. Hort. Sci. 114:661-665.

Kraak, H.L. and J. Vos. 1987. Seed viability constants for lettuce. Ann. Bot. (Lond.) 59:343-349.

Parera, C.A. and D.J. Cantliffe. 1994. Presowing seed priming. Hort. Rev. (Amer. Soc. Hort. Sci.) 16:109-145.

Pill, W.G. and E.A. Kilian. 2000. Germination and emergence of parsley in response to osmotic or matric seed priming and treatment with gibberellins. HortScience 35:907-909.

Roberts, E.H. 1986. Quantifying seed deterioration, p. 101-123. In: McDonald, M.B., Jr. and C.J. Nelson (eds.). Physiology of seed deterioration. CSSA Spec. Publ. No. 11. CSSA, Madison, WI.

Sun, W.Q., D.C.Y. Koh, and C.M. Ong. 1997. Correlation of modified water sorption properties with the decline of storage stability of osmotically-primed seeds of Vigna radiata (L.) Wilczek. Seed Sci. Res. 7:391-397.

Sun, W.Q., Y. Liang, S. Huang, and J. Fu. 2003. Biopolymer volume change and water clustering function of primed Vigna radiata seeds. Seed Sci. Res. 13:287-302.

Tarquis, A.M. and K.J. Bradford. 1992. Prehydration and priming treatments that advance germination also increase the rate of deterioration of lettuce seeds. J. Expt. Bot. 43:307-317.

Taylor, A.G., Y. Hadar, J.M. Norton, A.A. Kahn, and G.E. Harman. 1985. Influence of presowing seed treatments of table beet on the susceptibility to damping off caused by Pythium. J. Amer. Soc. Hort. Sci. 110:516-519.

Taylor, A.G. and G.E. Harman. 1990. Concepts and technologies of selected seed treatments. Ann. Rev. Phytopathol. 28:321-339.

Alvarado, A.D. and K.J. Bradford. 1989. Priming and storage of tomato (Lycopersicon lycopersicum) seeds. 1. Effect of storage temperature on germination rate and viability. Seed Sci. Technol. 16:601-612.
Valdes, V., K.J. Bradford, and K.S. Mayberry. 1985. Alleviation of thermodormancy in coated lettuce seed by seed priming. HortScience 20:1112-1114. 